\title{
Hydrogenative Kinetic Resolution of Vinyl Sulfoxides
}

\author{
Joan R. Lao, ${ }^{\dagger}$ Héctor Fernández-Pérez, ${ }^{\dagger}$ and Anton Vidal-Ferran*, ${ }^{\dagger}, *$ \\ $\dagger$ Institute of Chemical Research of Catalonia (ICIQ), Av. Països Catalans, 16, 43007 Tarragona, Spain \\ \$Catalan Institution for Research and Advanced Studies (ICREA), P. Lluís Companys, 23, 08010 Barcelona, Spain
}

\begin{abstract}
Enantiopure sulfoxides are valuable precursors of organosulfur compounds with a broad application in organic and pharmaceutical chemistry. An unprecedented strategy for obtaining highly enantioenriched sulfoxides based on a hydrogenative kinetic resolution using Rh-complexes of phosphine-phosphites ligands as catalysts is reported. After optimization, highly efficient conditions for the kinetic resolution of racemic sulfoxides have been identified. This methodology has been applied to a set of racemic aralkyl or aryl vinyl sulfoxides and allowed the isolation of both recovered and reduced product in excellent yields and enantioselectivities (up to $99 \%$ and $97 \%$ ee, respectively; 16 examples).
\end{abstract}

Optically pure sulfoxides are a valuable family of chiral compounds which have proven to be highly efficient chiral ligands ${ }^{1}$ as well as useful intermediates in the synthesis of relevant biologically active compounds. ${ }^{1 \mathrm{a}, 2}$ Among the approaches that asymmetric catalysis offers, kinetic resolution (KR) of racemic sulfoxides ${ }^{3}$ should be considered an appealing method for the preparation of two optically pure sulfoxides in only one synthetic step, provided that some requisites are fulfilled. First and foremost, it is necessary that efficient enantioselective catalysts working at low catalyst loadings are available and, second, that starting materials and products can be isolated in good yields and enantiomerically enriched forms. ${ }^{4}$

Whilst the reported nonenzymatic KRs on racemic sulfoxides are mainly based on oxidative transformations (Scheme 1, (a)), ${ }^{3,5}$ nonoxidative KRs, including reductive transformations (Scheme 1, (b)), have received much less attention. Moreover, nonoxidative KRs have normally offered unsatisfactory stereoselectivities, with the exception of enzymatic ${ }^{6}$ transformations and hydrogenative dynamic kinetic resolutions (DKR) of allyl sulfoxides. ${ }^{7}$ There are a few studies reporting reductive $\mathrm{KR}$ of vinyl sulfoxides with optically active reagents, ${ }^{8}$ however, to the best of our knowledge, there are no previous reports on the KR of vinyl sulfoxides via asymmetric hydrogenation. ${ }^{9}$ Classical kinetic resolution of sulfoxides
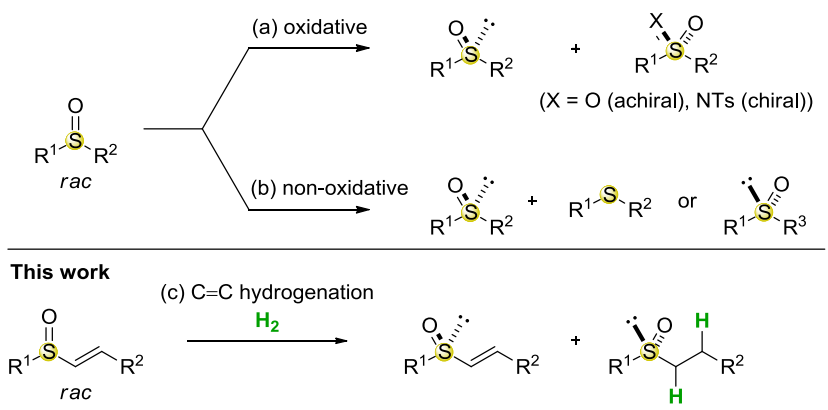

Scheme 1. Kinetic resolution strategies for racemic sulfoxides
Our group recently reported the highly enantioselective hydrogenation of a structurally diverse set of substrates mediated by phosphine-phosphite $(\mathrm{P}-\mathrm{OP})^{10}$ ligands. The high catalytic activities achieved with our ligands promted us to address the challenge of hydrogenatively resolving racemic vinyl sulfoxides (Scheme 1, (c)), whose resolved products have found broad applicability in catalytic asymmetric synthesis. ${ }^{1,2}$ Herein we describe our results, which include the catalyst optimization studies and the application of the lead-catalyst to the highly efficient hydrogenative $\mathrm{KR}$ of an array of racemic aralkyl or aryl vinyl sulfoxides. At the onset of our study, we chose phenyl vinyl sulfoxide rac-1a as model substrate. The reaction conditions and the results of this initial screening are summarized in Table 1.

Table 1. Ligand screening for the KR of $r a c-1 a^{a}$

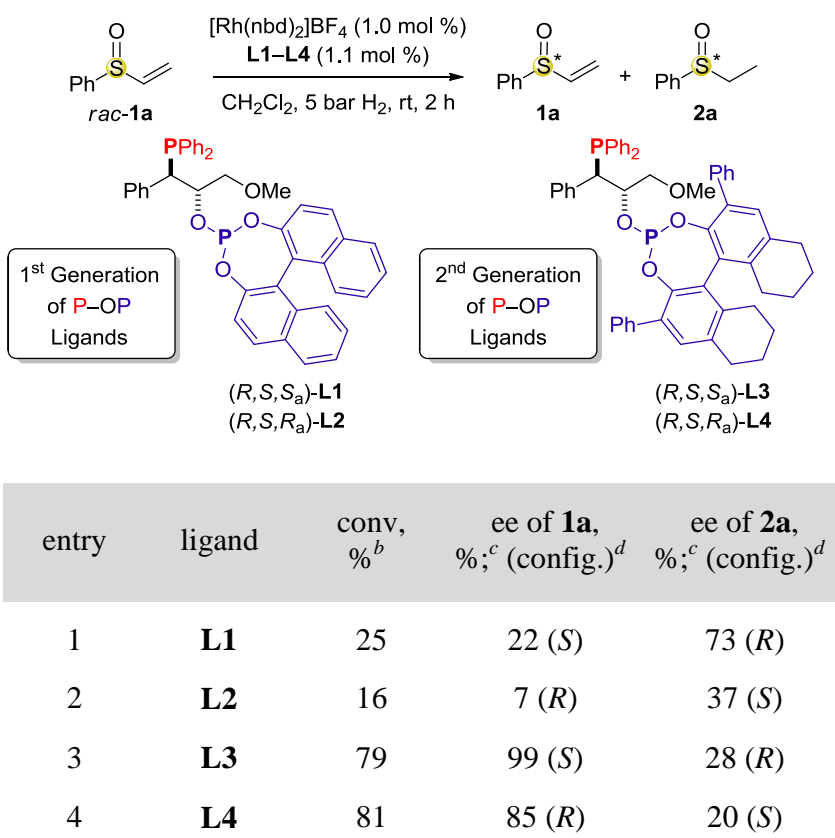

${ }^{a}$ [Substrate] $=0.2 \mathrm{M} .{ }^{b}$ Determined by ${ }^{1} \mathrm{H}$ NMR. ${ }^{c}$ Determined by HPLC on chiral stationary phases. ${ }^{d}$ The absolute configuration was assigned by comparison with reported data. 
As indicated in Table 1, both activity and selectivity were highly dependent on the $\mathrm{P}-\mathrm{OP}$ ligand used. Rhodium complexes derived from ligands $\mathbf{L} \mathbf{1}$ and $\mathbf{L} 2$ afforded the hydrogenated product $\mathbf{2 a}$ with $37-73 \%$ ee, though conversions were very low and ee values for the recovered starting material 1a poor (see entries 1 and 2 in Table 1). In contrast, rhodium complexes of the new ligands $\mathbf{L 3}$ and $\mathbf{L} \mathbf{4}$ displayed an opposite trend with high conversions and excellent enantioselectivities for 1a (up to 99\% ee) (see entries 3 and 4 in Table 1). Therefore, these results clearly identified $\mathbf{L 1}$ and $\mathbf{L 3}$ as the optimal ligands for this chemistry with the stereogenic phosphite group being the principal stereochemical director (opposite absolute configurations for sulfoxides $\mathbf{1 a}$ and $\mathbf{2 a}$ are obtained depending on the configuration of the phosphite group: compare entries 1 with 2 for $\mathbf{L} \mathbf{1}$ and $\mathbf{L 2}$, or entries 3 with 4 for $\mathbf{L 3}$ and $\mathbf{L} 4$ in Table 1, respectively).

Next, we proceeded to optimize the reaction conditions with P-OP ligands $\mathbf{L 1}$ and $\mathbf{L 3}$ in a range of different solvent mixtures. ${ }^{11}$ The assayed reaction conditions and results are shown in Table 2.

Table 2. Solvent optimization using ligands $\mathrm{L1}$ or $\mathrm{L3}^{a}$

\begin{tabular}{|c|c|c|c|c|c|c|c|}
\hline $\mathrm{Ph}^{\mathrm{O}-\mathrm{O}}$ & & 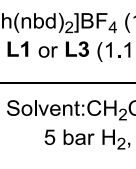 & $\begin{array}{l}.0 \mathrm{~mol} \% \\
\mathrm{~mol} \%) \\
\mathrm{I}_{2}(4: 1) \\
\mathrm{t}, t\end{array}$ & (s & 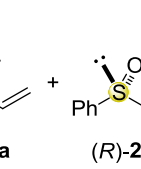 & & $3 a$ \\
\hline entry & $\mathrm{L}$ & solvent & $t, \mathrm{~h}$ & $\begin{array}{c}\text { conv, } \\
\%^{b}\end{array}$ & $1 \mathbf{a}: \mathbf{2 a}: 3 \mathbf{a}^{b}$ & $\begin{array}{c}\text { ee of } \\
\text { 1a, \% }{ }^{c} \\
(S)^{d}\end{array}$ & $\begin{array}{l}\text { ee of } \\
\mathbf{2 a}, \% ;^{c} \\
(R)^{d}\end{array}$ \\
\hline 1 & L1 & $\mathrm{Cy}$ & 2 & 56 & $44: 34: 12$ & 99 & 80 \\
\hline 2 & L1 & $\mathrm{MeOH}$ & 2 & 10 & $90: 6: 4$ & 9 & 73 \\
\hline 3 & L1 & MeTHF $^{e}$ & 2 & 44 & $56: 42: 2$ & 65 & 83 \\
\hline 4 & L1 & Toluene & 2 & 56 & $44: 52: 4$ & 92 & 76 \\
\hline 5 & $\mathbf{L 1}$ & $\mathrm{CH}_{2} \mathrm{Cl}_{2}$ & 2 & 25 & $75: 25: 0$ & 22 & 73 \\
\hline 6 & $\mathbf{L 3}$ & Cy & 1 & 54 & $46: 54: 0$ & 99 & 72 \\
\hline 7 & L3 & $\mathrm{MeOH}$ & 1 & 79 & 21:79:0 & 99 & 28 \\
\hline 8 & $\mathbf{L 3}$ & $\mathrm{MeTHF}^{e}$ & 1 & 60 & 40:60:0 & 99 & 64 \\
\hline 9 & $\mathbf{L 3}$ & Toluene & 1 & 58 & 42:58:0 & 99 & 64 \\
\hline 10 & $\mathbf{L 3}$ & $\mathrm{CH}_{2} \mathrm{Cl}_{2}$ & 1 & 68 & $32: 68: 0$ & 99 & 45 \\
\hline
\end{tabular}

$a, b, c, d$ See notes $a, b, c$ and $d$ in Table $1 .{ }^{e}$ MeTHF $\equiv 2$-methyltetrahydrofuran.

According to these results, a mixture of cyclohexane and $\mathrm{CH}_{2} \mathrm{Cl}_{2}$ was identified as the optimal solvent for rac-1a as it provided the highest ee values for sulfoxides $\mathbf{1 a}$ and $\mathbf{2 a}$ (see entries 1 and 6 in Table 2). Unfortunately, the rhodium complex derived from ligand $\mathbf{L} \mathbf{1}$ led to the formation of significant amounts of ethyl phenyl sulfide 3a as byproduct arising from the overreduction of the starting material (see entry 1 in Table 2). ${ }^{12}$ This phenomenon was also observed for $\mathbf{L} \mathbf{1}$ in all the mixtures of solvents tested (see entries 1 to 4 in Table 2). However, we were pleased to find that this side reaction was completely eliminated by using the rhodium complex derived from the P-OP ligand L3. Moreover, this catalyst provided at $54 \%$ conversion the recovered vinyl sulfoxide $1 \mathrm{a}$ in a perfect enantioselectivity (up to $99 \%$ ee in favor of the $(S)$ - enantiomer) and the corresponding hydrogenated product $2 \mathbf{a}$ (see entry 6 in Table 2).

With the optimal catalyst in hand, we then attempted to broaden the substrate scope to a set of structurally diverse vinyl sulfoxides $(\mathrm{rac}-\mathbf{1 a}-\mathbf{h})$. In order to maximize the yield for both the recovered and hydrogenated products $(\mathbf{1} \mathbf{a}-\mathbf{h}$ and $\mathbf{2} \mathbf{a}-\mathbf{h}$, respectively), specific reaction conditions for $\mathbf{1} \mathbf{a}-\mathbf{h}$ and for $\mathbf{2} \mathbf{a}-\mathbf{h}$ were investigated. ${ }^{13}$ The results and optimized reaction conditions are listed in Table 3.

Table 3. Substrate scope of the hydrogenative KR of racemic vinyl sulfoxides $r a c-1 a-h^{a}$

\begin{tabular}{|c|c|c|c|c|c|}
\hline $\mathrm{R}^{-S}$ & $\begin{array}{r}{[\mathrm{Rh}(\mathrm{n}} \\
\mathrm{P}-\mathrm{OP} \\
\end{array}$ & $\begin{array}{l}\mathrm{bd})_{2} \mathrm{BF}_{4}(1 \\
\text { ligand } \mathrm{L3} \text { ( } \\
5 \mathrm{C}: \mathrm{CH}_{2} \mathrm{Cl}_{2} \\
5 \text { bar } \mathrm{H}_{2}, \mathrm{r}\end{array}$ & $\begin{array}{l}\mathrm{mol} \%) \\
\mathrm{mol} \%)\end{array}$ & 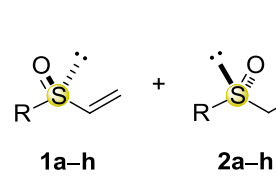 & \\
\hline entry & $\mathrm{R}$ & $t, \min$ & $\begin{array}{c}\text { conv } \\
\%^{b}\end{array}$ & $\begin{array}{c}\text { product, isol. yield, } \\
\% ;^{14} \\
\left.\text { ee, } \% ;^{c} \text { (config. }\right)^{d}\end{array}$ & $\mathrm{~s}^{e}$ \\
\hline $1^{f}$ & $\mathrm{Ph}$ & 60 & 54 & 1a, 74, $99(S)$ & 30 \\
\hline 2 & $(r a c-\mathbf{1 a})$ & 30 & 44 & $\mathbf{2 a}, 62,86(R)$ & 35 \\
\hline 3 & $p$-Me-Ph & 80 & 55 & $\mathbf{1 b}, 74, \mathbf{9 8}(S)$ & 25 \\
\hline 4 & $(r a c-\mathbf{1 b})$ & 10 & 35 & $\mathbf{2 b}, 58,95(R)$ & 55 \\
\hline 5 & $o-\mathrm{F}-\mathrm{Ph}$ & 15 & 55 & 1c, $80,99(S)$ & 56 \\
\hline 6 & $(r a c-1 c)$ & 8 & 42 & 2c, $80,97(R)$ & 148 \\
\hline 7 & $m$-F-Ph & 30 & 61 & 1d, 54, $98(S)$ & 25 \\
\hline 8 & $(r a c-\mathbf{1 d})$ & 10 & 39 & 2d, 76, $92(R)$ & 44 \\
\hline 9 & $p$-F-Ph & 30 & 54 & $1 \mathrm{e}, 70,98(S)$ & 33 \\
\hline 10 & $(r a c-1 e)$ & 15 & 44 & $2 \mathrm{e}, 56,90(R)$ & 40 \\
\hline 11 & $p$-MeO-Ph & 120 & 64 & 1f, 64, $99(S)$ & 26 \\
\hline 12 & $(r a c-\mathbf{1 f})$ & 30 & 39 & $\mathbf{2 f}, 76, \mathbf{8 8}(R)$ & 29 \\
\hline 13 & $p$-NO2-Ph & 25 & 66 & 1g, 64, $99(S)$ & 13 \\
\hline 14 & $(r a c-1 g)$ & 10 & 40 & $\mathbf{2 g}, 72,82(R)$ & 18 \\
\hline $15^{g}$ & $\mathrm{Bn}$ & 240 & 67 & 1h, $62,99(R)^{h}$ & 11 \\
\hline $16^{g}$ & $(r a c-\mathbf{1 h})$ & 25 & 33 & $\mathbf{2 h}, 56, \mathbf{8 0}(S)^{h}$ & 13 \\
\hline
\end{tabular}

${ }^{a, b, c}$ See notes $a, b$ and $c$ in Table $1 .{ }^{d}$ The absolute configuration of $\mathbf{1} \mathbf{a}, \mathbf{b}$ and $\mathbf{2 a}, \mathbf{b}, \mathbf{f}-\mathbf{h}$ was established by comparison with reported optical rotations. The absolute configuration of $\mathbf{1 c}-\mathbf{h}$ and $\mathbf{2 c}-\mathbf{e}$ was tentatively assigned by analogy with the stereochemical

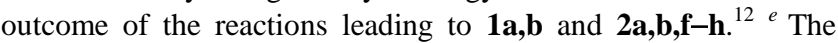
selectivity factor $(\mathrm{s})^{4}$ was determined by the equation $\mathrm{s}=$ $k_{\text {rel }}($ fast $/$ slow $)=\ln \left[1-\mathrm{C}\left(1+\mathrm{ee}_{2}\right)\right] / \ln \left[1-\mathrm{C}\left(1-\mathrm{ee}_{2}\right)\right] .{ }^{f}$ This result has been already shown in Table $2 .^{g}$ Solvent ratio used was Cy: $\mathrm{CH}_{2} \mathrm{Cl}_{2}(2.6: 1) .{ }^{h}$ The opposite $R$ or $S$ prefixes in $\mathbf{1 h}$ and $\mathbf{2 h}$ arise from different priorities in the CIP rules.

As illustrated in Table 3, different substitution patterns on the aryl groups of vinyl sulfoxides rac-1c-e $(o-\mathrm{F}, m-\mathrm{F}$ and $p-\mathrm{F}$ substitution, respectively) were well tolerated to furnish sulfoxides $2 \mathbf{c}-\mathbf{e}$ in $56-80 \%$ isolated yield ${ }^{14}$ with $90-97 \%$ ee, and the recovered vinyl sulfoxides $1 \mathbf{c}-\mathbf{e}$ in $54-80 \%$ isolated yield ${ }^{14}$ with very high enantioselectivities $(98-99 \%$ ee; see entries 5-10 in Table 3). The results obtained for the ortho- 
substituted substrate rac-1c were the best among all the substrates assessed (see entries 5 and 6 in Table 3). Plots of ee values of resolved products against conversion displayed that the highest enantioselectivities for such compounds were achieved in the range of 40-60\% conversion (see Figure 1, which corresponds to the KR of substrate $r a c$-1c), demonstrating the high efficiency of this KR to provide unreacted starting material and hydrogenated product in high yields and ee's.

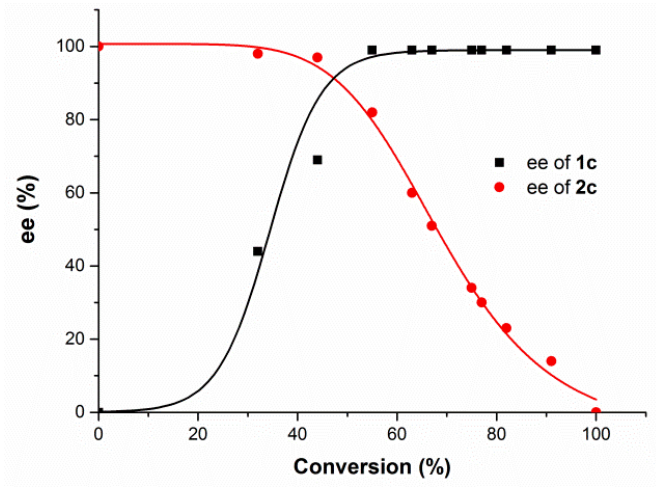

Figure 1. Ee values (\%) of $1 \mathrm{c}$ and $2 \mathrm{c}$ vs. conversion (\%).

Electronic effects were also studied by the examination of para-substituted substrates rac-1b,e,f,g ( $p$-Me, $p$-F, $p$-MeO, $p$ $\mathrm{NO}_{2}$, respectively). Regardless of the electronic nature of the substituent on the aromatic ring, the substrates were hydrogenated leading to both unreacted and reduced sulfoxides with high enantioselectivities (from 82 to $99 \%$ ee) in $56-76 \%$ isolated yields ${ }^{14}$ (see entries 3,4 and 9-14 in Table 3). However, an electron withdrawing group at the para-position increased the reaction rate (compare entries 9, 10 and 13, 14 with entries 3, 4 and 11, 12 in Table 3). The lead catalytic system was also capable of efficiently resolving benzyl vinyl sulfoxide (rac1h): Hydrogenation of $\mathrm{rac}-\mathbf{1 h}$ for 4 h provided $(R)-\mathbf{1 h}$ in $62 \%$ isolated yield ${ }^{14}$ with perfect enantioselectivity $(99 \%$ ee, see entry 15 in Table 3), while optimal reaction conditions for the hydrogenated product $(S)$-2h led to its isolation in 56\% isolated yield ${ }^{14}$ and $80 \%$ ee (see entry 16 in Table 3 ). In order to demonstrate the practicality of this KR method, experiments at the mmol scale were performed for racemic substrates rac1a,g to afford products 1a,g and 2a,g with the same efficiency than catalytic experiments. ${ }^{12}$

To shed light on the favored stereodifferentiating routes, we studied the coordination of $(R)-\mathbf{1 g}$ and $(S)-\mathbf{1 g}$ to the $[\mathrm{Rh}(\mathrm{P}-\mathrm{OP})]^{+}$complex of the lead ligand $(\mathbf{L 3})$. We pursued the in situ preparation of $[\mathrm{Rh}(\mathbf{1 g})(\mathbf{L 3})] \mathrm{BF}_{4}$ by hydrogenation of $[\mathrm{Rh}(\mathrm{nbd})(\mathbf{L} \mathbf{3})] \mathrm{BF}_{4}$ in 1,2- dimethoxyethane followed by the addition of 1.1 equiv. of $(R)-\mathbf{1 g}$ or $(S)-\mathbf{1 g}$. Based on related literature precedents, ${ }^{7,9}$ we hypothesized that the KR proceeds via hydrogenation of the $\mathrm{C}=\mathrm{C}$ bond with chelating assistance of the oxygen atom ofthe sulfoxide group. Examination of the NMR data in solution indicated that both $(R)-\mathbf{1 g}$ and $(S)-\mathbf{1 g}$ coordinate to the $[\mathrm{Rh}(\mathrm{P}-\mathrm{OP})]^{+}$motif. The coordination of $(S)$ $\mathbf{1 g}$ led to the formation of a stable complex at rt, as evidenced by the sharpness of the vinylic signals in the ${ }^{1} \mathrm{H}$ NMR spectrum. ${ }^{12}$ The formation of the substrate-catalyst adduct $[\mathrm{Rh}((R)-$ $\mathbf{~} \mathbf{g})(\mathbf{L 3})]^{+}$was evidenced by the appearance of broad vinylic signals in the ${ }^{1} \mathrm{H}$ NMR spectrum, which sharpened up upon recording the spectra at a lower temperature $(253 \mathrm{~K})$. With regard to the geometry of the complexes between $(R)-\mathbf{1 g}$ or $(S)-\mathbf{1 g}$ and the $[\mathrm{Rh}(\mathrm{P}-\mathrm{OP})]^{+}$motif, cross-peaks only between the olefinic protons and the phosphino group in heteronuclear ${ }^{1} \mathrm{H}-{ }^{31} \mathrm{P}$ correlation experiments were observed. ${ }^{12}$ These obser- vations strongly suggest that the $\mathrm{C}=\mathrm{C}$ bonds of $(R)$-1g and $(S)$ $\mathbf{1 g}$ are coordinated to the phosphino group in a cis fashion, as this data is practically coincident with that reported in the literature for cis-coordinated $\mathrm{C}=\mathrm{C}$ and phosphorus groups in related rhodium complexes. ${ }^{15}$ Furthermore, intense crosspeaks between the olefinic $\mathrm{H}-\mathrm{C}_{\beta}$ proton trans to $\mathrm{H}-\mathrm{C}_{\alpha}$ and aromatic protons of the diphenylphosphino group in NOESY correlation experiments were observed for bound $(S)-\mathbf{1 g}$, thus confirming the previous structural assignment. ${ }^{12}$ This coordination mode of the $\mathrm{C}=\mathrm{C}$ double bond places the $\mathrm{R}$ group of the sulfoxide in close proximity to the phosphite group, which accounts for this group being the principal stereochemical director in the KR. By comparing the results of these coordination studies and the configuration of the resolved products, a tentative reaction pathway for the stereochemical outcome of the $\mathrm{KR}$ is proposed in Figure 2.
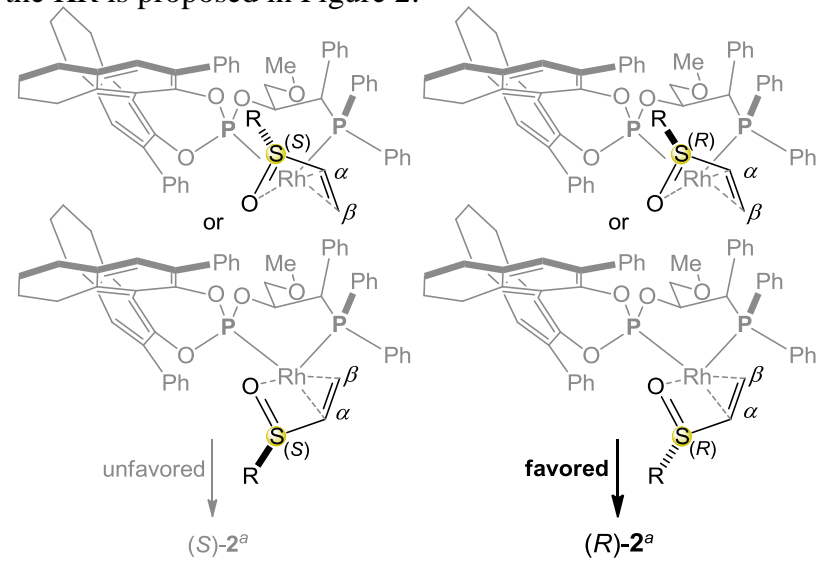

Figure 2. Tentative reaction pathways for the hydrogenative $\mathrm{KR}$ of racemic vinyl sulfoxides in the $\mathrm{Rh}-\mathbf{L} \mathbf{3}$ complexes with the $\mathrm{C}=\mathrm{C}$ and $\mathrm{P}$ groups coordinated in a cis fashion $\left({ }^{a} R\right.$ or $S$ configurations of the product have been established assuming the highest CIP's priority for the $\mathrm{R}$ group).

In summary, we have developed a highly efficient hydrogenative KR of vinyl sulfoxides mediated by rhodium complexes of P-OP ligand $\mathbf{L 3}$, which are responsible for the differentiation of the reaction rates of the two enantiomers of the starting material toward hydrogenation. This KR method is an unprecedented approach for preparing optically active vinyl sulfoxides and their hydrogenated products in notable yields and high enantioselectivities (up to $99 \%$ ee). The easy availability of racemic vinyl sulfoxides, together with the excellent catalytic profile of the catalyst derived from $\mathbf{L 3}$, makes the herein described synthetic methodology a valuable synthetic entry for chiral sulfoxides. Further studies on the application of this synthetic methodology, together with mechanistic investigations, are underway in our laboratory and will be reported in due course.

\section{ASSOCIATED CONTENT}

\section{Supporting Information}

The Supporting Information is available free of charge on the ACS publications website at DOI: 10.1021/acs.orglett.5b02139.

Experimental procedures, spectral data, and determination of the enantiomeric excess. (PDF)

\section{AUTHOR INFORMATION}

\section{Corresponding Author}

*E-mail: avidal@iciq.cat 


\section{Notes}

The authors declare no competing financial interest.

\section{ACKNOWLEDGMENT}

The authors thank MINECO (CTQ2014-60256-P and Severo Ochoa Excellence Accreditation SEV-2013-0319) and the ICIQ Foundation for financial support. J.-R. L. thanks the ICIQ Foundation for a pre-doctoral fellowship. Dr. P. Etayo (ICIQ) is acknowledged for discussions at the beginning of the project.

\section{REFERENCES}

(1) For selected recent reviews, see: (a) Fernández, I.; Khiar, N. Chem. Rev. 2003, 103, 3651. (b) Fernández, I. and Khiar, N. In Organosulfur Chemistry in Asymmetric Synthesis; Toru, T. and Bolm, C., Eds.; WILEY-VCH Verlag GmbH \& Co. KGaA: Weinheim, 2008; p 265. (c) Trost, B. M.; Rao, M. Angew. Chem., Int. Ed. 2015, 54, 5026. (d) Sipos G.; Drinkel, E. E.; Dorta, R. Chem. Soc. Rev. 2015, 44, 3834.

(2) For a recent review, see: Legros, J.; Dehli, J. R.; Bolm, C. Adv. Synth. Catal. 2005, 347, 19.

(3) For example, see: Kagan, H. B. In Organosulfur Chemistry in Asymmetric Synthesis; Toru, T. and Bolm, C., Eds.; WILEY-VCH Verlag GmbH \& Co. KGaA: Weinheim, 2008; p 1.

(4) Keith, J. M.; Larrow, J. F.; Jacobsen, E. N. Adv. Synth. Catal. 2001, 343, 5 .

(5) The following article has been selected as an oxidative method considering oxidative as all transformations in which the formal oxidation state of the S-atom increases: Wang, J.; Frings, M.; Bolm, C. Chem. - Eur. J. 2014, 20, 966.

(6) For selected examples on enzymatically catalyzed KRs, see for example: (a) Boyd, D. R.; Sharma, N. D.; King, A. W. T.; Shepherd, S. D.; Allen, C. C. R.; Holt, R. A.; Luckarift, H. R.; Dalton, H. Org. Biomol. Chem. 2004, 2, 554. (b) Boyd, D. R.; Sharma, N. D.; Byrne, B. E.; Haughey, S. A.; Kennedy, M. A.; Allen, C. C. R. Org. Biomol. Chem. 2004, 2, 2530.

(7) Though DKRs are not the same as the aimed transformations in this manuscript (KRs), the following reference on DKR of allyl sulfoxides has been included due to the high enantioselectivities achieved (up to 90\% ee): Dornan, P. K.; Kou, K. G. M.; Houk, K. N.; Dong, V. M. J. Am. Chem. Soc. 2014, 136, 291.

(8) (a) Mikolajczyk, M.; Para, M. J. Chem. Soc. D 1969, 1192. (b) Mikolajczyk, M.; Drabowicz, J. Phosphorous Sulfur Relat. Elem. 1976, 1, 301. (c) Drabowicz, J.; Pacholczyk, M. Phosphorous Sulfur Relat. Elem. 1981, 10, 233. (d) Annunziata, R.; Borgogno, G.; Montanari, F.; Quici, S.; Cucinella, S. J. Chem. Soc., Perkin Trans. 1 1981, 113.

(9) To best of our knowledge, the only reported transformation, which is close to the chemistry herein described (see: Ando, D.; Bevan, C.; Brown, J. M.; Price, D. W. J. Chem. Soc., Chem. Commun. 1992, 592.), involves asymmetric hydrogenation of vinyl sulfoxides and kinetic resolution of one vinyl sulfone.

(10) For selected references on the application of $\mathrm{P}-\mathrm{OP}$ ligands in iridium-mediated hydrogenations, see: (a) Núñez-Rico, J. L.; Fernández-Pérez, H.; Benet-Buchholz, J.; Vidal-Ferran, A. Organometallics 2010, 29, 6627. (b) Núñez-Rico, J. L.; Vidal-Ferran, A. Org. Lett. 2013, 15, 2066. (c) Núñez-Rico, J. L.; Fernández-Pérez, H.; Vidal-Ferran, A. Green Chem. 2014, 16, 1153. For those on rhodium-mediated hydrogenation, see: (d) Donald, S. M. A.; VidalFerran, A.; Maseras, F. Can. J. Chem. 2009, 87, 1273. (e) FernándezPérez, H.; Donald, S. M. A.; Munslow, I. J.; Benet-Buchholz, J.; Maseras, F.; Vidal-Ferran, A. Chem. - Eur. J. 2010, 16, 6495. (f) Etayo, P.; Núñez-Rico, J. L.; Fernández-Pérez, H.; Vidal-Ferran, A. Chem. - Eur. J. 2011, 17, 13978. (g) Núñez-Rico, J. L.; Etayo, P.; Fernández-Pérez, H.; Vidal-Ferran, A. Adv. Synth. Catal. 2012, 354, 3025. (h) Fernández-Pérez, H.; Benet-Buchholz, J.; Vidal-Ferran, A. Chem. - Eur. J. 2014, 20, 15375.

(11) A certain amount of $\mathrm{CH}_{2} \mathrm{Cl}_{2}$ was kept in order to ensure the complete solubility of both rhodium precursor and ligand.

(12) See the Supporting Information for further details.

(13) The reaction conditions were optimized by modifying the reaction times, (controlling in this way the value of conversion), in an optimal compromise amongst enantiopurity and amounts of unreacted starting material and product.

(14) Yields are calculated with respect to the $50 \mathrm{~mol} \%$ amount of starting material that was subjected to KR.

(15) (a) Bircher, H; Bender, B. R.; Philipsborn, W. v. Magn. Reson. Chem. 1993, 31, 293. (b) Gridnev, I. D.; Higashi, N.; Asakura, K.; Imamoto, T. J. Am. Chem. Soc. 2000, 122, 7183. (c) Suárez, A.; Méndez-Rojas, M. A.; Pizzano, A. Organometallics 2002, 21, 4611. 
